\title{
Inhibition of macrophage activation and lipopolysaccaride-induced death by seco-steroids purified from Physalis angulata $\mathrm{L}$.
}

\author{
Milena B.P. Soares ${ }^{\mathrm{a}, *}$, Moema C. Bellintani ${ }^{\mathrm{a}}$, Ivone M. Ribeiro ${ }^{\mathrm{b}}$, \\ Therezinha C.B. Tomassini ${ }^{\mathrm{b}}$, Ricardo Ribeiro dos Santos ${ }^{\mathrm{a}}$ \\ ${ }^{a}$ Centro de Pesquisas Gonçalo Moniz, Rua Waldemar Falcão, 121-Brotas-FIOCRUZ, Salvador 40295-001 BA, Brazil \\ ${ }^{\mathrm{b}}$ FarManguinhos, FIOCRUZ, Rio de Janeiro, RJ, Brazil
}

Received 22 April 2002; received in revised form 20 November 2002; accepted 22 November 2002

\begin{abstract}
Physalis angulata L. is an annual herb widely used in popular medicine for the treatment of a variety of pathologies. Here, we tested immunomodulatory activities of physalins, seco-steroids purified from P. angulata extracts. Addition of physalins B, F or G, but not D, caused a reduction in nitric oxide production by macrophages stimulated with lipopolysaccaride and interferon- $\gamma$. In the presence of physalin B, macrophages stimulated with lipopolysaccaride, alone or in combination with interferon- $\gamma$, produced lower levels of tumour necrosis factor (TNF)- $\alpha$, interleukin- 6 and interleukin-12. The inhibitory activity of physalin B, unlike that of dexamethasone, was not reversed by RU486 [(4-dimethylamino) phenyl-17ß-hydroxy-17-(1-propynyl)estra-4,9-dien-3-one], an antiglucocorticoid. Physalin B-treated mice had lower levels of serum TNF- $\alpha$ than control mice after lipopolysaccaride challenge. More importantly, mice injected with physalins B, F or G survived after a lethal lipopolysaccaride challenge. These results demonstrate that seco-steroids from $P$. angulata are potent immunomodulatory substances and act through a mechanism distinct from that of dexamethasone.
\end{abstract}

(C) 2002 Elsevier Science B.V. All rights reserved.

Keywords: Steroid; Immunomodulation; (Physalis angulata L.); Endotoxic shock

\section{Introduction}

Glucocorticoids are potent modulators of inflammatory responses, exerting their effects in a variety of cell types, including macrophages and lymphocytes. They cause the suppression of immune-inflammatory responses and act by suppressing cell activation events, as well as modulating the production of several mediators, including arachidonic acid metabolites such as prostaglandins and leukotrienes, acutephase reactants and several cytokines (Schimmer and Parker, 2001). The activities of glucocorticoids are mediated by the glucocorticoid receptor, which is a member of a superfamily of ligand-inducible transcription regulators for steroids and thyroid hormones (Beato and Klug, 2000; Duarte et al., 2002; Mangelsdorf et al., 1995). Upon binding to its ligands, the glucocorticoid receptor acts as a transactivator of responsive

* Corresponding author. Tel.: +55-71-356-4320; fax: +55-71-356-2155.

E-mail address: milena@cpqgm.fiocruz.br (M.B.P. Soares). genes, as well as negative regulator of gene transcription (Beato and Klug, 2000).

Macrophage activation by lipopolysaccaride, the major component of gram-negative bacteria cell wall, results in the release of several inflammatory mediators such as nitric oxide (NO) and the proinflammatory cytokines tumour necrosis factor (TNF)- $\alpha$, interleukin-6 and interleukin-12. The exacerbated production of these mediators by activated macrophages has deleterious consequences in septicemia or endotoxemia, and may lead to hypotension, disseminated intravascular coagulation, neutrophil extravasation, tissue hypoxia and death (Schimmer and Parker, 2001). Glucocorticoids and other steroid hormones inhibit the production of proinflammatory cytokines and NO by activated macrophages and protect against lipopolysaccaride-induced death. Administration of the synthetic glucocorticoid dexamethasone decreases while treatment with RU486 [(4-dimethylamino) phenyl-17 $\beta$-hydroxy-17-(1-propynyl)estra-4,9-dien3 -one], a glucocorticoid receptor antagonist, increases the lipopolysaccaride-induced mortality in mice (Lazar et al., 1992). 
Physalis angulata belongs to the Solanaceae family and is widely distributed throughout tropical and subtropical regions of the world. Extracts or infusions from this plant have been used in various countries in popular medicine as a treatment for a variety of illnesses, such as malaria, asthma, hepatitis, dermatitis and rheumatism (Lin et al., 1992; Chiang et al., 1992b). Several compounds from $P$. angulata have been isolated and chemically characterized. A group of steroids, known as physalins, are found in $P$. angulata stems and leaves (Lin et al., 1992). Antitumoral activities of purified physalins have been described (Chiang et al., 1992a,b). In this report, we have analyzed the immunomodulatory activity of physalins purified from $P$. angulata in activation-induced macrophage cytokine and nitric oxide production and in a murine model of endotoxic shock.

\section{Materials and methods}

\subsection{Mice}

$\mathrm{BALB} / \mathrm{c}$ mice (male and female), 6-10 weeks old, were used to obtain cells from peritoneal cell exudate. Male, 6week-old $\mathrm{BALB} / \mathrm{c}$ mice were used in lipopolysaccarideinduced shock experiments. All mice were raised and maintained at the animal facilities at the Gonçalo Moniz Research Center-FIOCRUZ, and provided with rodent diet and water ad libitum. Animal numbers in experimental groups were the minimum necessary to allow statistical analysis. All animals were sacrificed under anaesthesia.

\subsection{Physalin purification}

P. angulata $\mathrm{L}$. stems ethanolic extracts $(15 \mathrm{~g})$, obtained from dried plant material (collected at Belém do Pará, Brazil), were dissolved in $300 \mathrm{ml}$ of methanol and mixed for $2 \mathrm{~h}$ with a lead acetate solution $(25 \mathrm{~g}$ in $200 \mathrm{ml}$ of distilled hot water). Twenty grams of activated charcoal (Merck Darmstadt, Germany) were added to the mixture and stirred up. The solution was then filtered and poured into a separatory funnel and extracted three times with $200 \mathrm{ml}$ of chloroform. The chloroform layers $(600 \mathrm{ml})$ were evaporated under reduced pressure giving $700 \mathrm{mg}$ of a solid material (pool of physalins). This pool was chromatographed using a liquid medium pressure chromatographic column (MPLC). The elution was carried out with a gradient solvent system (hexane-ethyl acetate 7:3; thru 100\% ethyl acetate). The collected fractions, after evaporation, were assayed in thin layer chromatography (TLC), against standard physalins. The substances, after recrystallizations in ethyl acetate, gave the following results: $15 \mathrm{mg}$ of physalin B ( $96 \%$ of purity), $75 \mathrm{mg}$ of physalin D (95.6\% of purity), $56 \mathrm{mg}$ of physalin $\mathrm{F}(97.8 \%$ of purity) and $51 \mathrm{mg}$ of physalin G (95\% of purity). The chemical structures of physalins are described elsewhere (Matsuura et al., 1970;
Mulchandani et al., 1979; Row et al., 1978; Row et al., 1980).

\subsection{Macrophage cultures}

Peritoneal exudate cells were obtained by washing with cold Hank's balanced salt solution (HBSS; Life Technologies, GIBCO-BRL, Gaithersburg, MD) the peritoneal cavity of mice 5 days after injection of $3 \%$ thioglycollate in saline ( $1.5 \mathrm{ml}$ per mouse). Cells were washed twice with HBSS and resuspended in RPMI medium (GIBCO-BRL) supplemented with $10 \%$ fetal calf serum (Hyclone, Logan, UT), L-glutamine $(2 \mathrm{mM})$, vitamins, sodium pyruvate $(1 \mathrm{mM})$, HEPES $(10 \mathrm{mM}), 2$-mercaptoethanol $(50 \mu \mathrm{M})$ and gentamycin $(50$ $\mu \mathrm{g} / \mathrm{ml}$ ) (Sigma, St. Louis, MO). For TNF- $\alpha$ and interleukin-6 determinations, $5 \times 10^{6}$ cells/well were plated in 24 -well plates. For interleukin-12 and nitric oxide determinations, $2 \times 10^{5}$ cells/well were plated in 96-well plates. After $1 \mathrm{~h}$ of incubation at $37{ }^{\circ} \mathrm{C}$, nonadherent cells were removed by washing with complete RPMI. Cultures were then stimulated with lipopolysaccaride (from Escherichia coli serotype 0111:B4, Sigma) alone or in combination with interferon- $\gamma$ (PharMingem, San Diego, CA) and treated with various concentrations of physalins or dexamethasone (Sigma), as described in figure legends. The glucocorticoid receptor antagonist RU486 (Sigma) was added in some cultures at a final concentration of $10 \mu \mathrm{M}$. Cell-free supernatants were collected at $6 \mathrm{~h}$ for determination of TNF- $\alpha$ and interleukin- 6 concentrations and at $24 \mathrm{~h}$ for interleukin-12 and NO concentrations.

\subsection{Endotoxic shock}

Groups of mice were intraperitoneally (i.p.) injected with a dose of $600 \mu \mathrm{g}$ of lipopolysaccaride in saline (previously determined as LD 100) alone or in combination with 0.5 or 1 $\mathrm{mg}$ of physalins. Mice were monitored daily for 4 days. To determine serum TNF- $\alpha$ levels, mice were sacrificed $90 \mathrm{~min}$ after injection of $400 \mu \mathrm{g}$ of lipopolysaccaride alone or in combination with $0.5 \mathrm{mg}$ of physalin B and bled by axilar vein puncture.

\subsection{Cytokine and NO determinations}

TNF- $\alpha$, interleukin- 6 and interleukin-12 (p40) concentrations in serum samples or in supernatants from macrophage cultures were determined by enzyme-linked immunosorbent assay (ELISA) using antibody pairs from PharMingen, according to the manufacturer's instructions. After incubation with streptoavidin-peroxidase conjugate (Sigma), the reaction was developed using 3,3',5,5'-tetramethylbenzidine (TMB) peroxidase substrate (Kinkergaard \& Perry Laboratories, Gaithersburg, MD) and read at $450 \mathrm{~nm}$. Nitric oxide production was estimated by measuring nitrite content in supernatants using the Griess method, as described previously (Ding et al., 1988). 


\subsection{Statistical analyses}

Data were analyzed using Student's $t$-test, one-way analysis of variance (ANOVA) or Newman-Keuls multiple comparison test. Differences were considered significant when $P<0.05$.

\section{Results}

3.1. Physalins $B, F$ or $G$, but not $D$, inhibit nitric oxide production by activated macrophages

Addition of physalins B, F, or G to macrophage cultures stimulated with lipopolysaccaride and interferon- $\gamma$ caused a dose-dependent inhibition in nitric oxide $(\mathrm{NO})$ production by macrophage cultures stimulated with lipopolysaccaride and interferon- $\gamma$, as indicated by the nitrite concentrations in supernatants (Fig. 1A). In contrast, addition of physalin D did not cause any inhibition in NO production (Fig. 1A). Physalin $\mathrm{F}$ was significantly more active than physalins $\mathrm{B}$ and $\mathrm{G}$ at $0.2 \mu \mathrm{g} / \mathrm{ml}(P>0.01)$. At a dose of $2 \mu \mathrm{g} / \mathrm{ml}(0.5 \mu \mathrm{M})$, physalin B reduced by $90 \%$ the NO production, whereas 1 $\mu \mathrm{M}$ of dexamethasone reduced only about $30 \%$ (Fig. 1B).
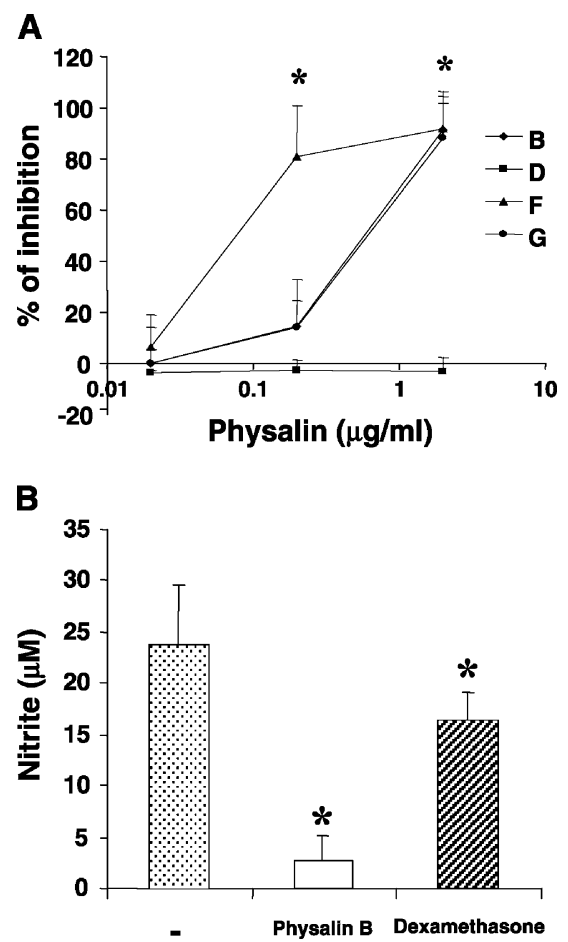

Fig. 1. Effects of different physalins on NO production by activated macrophages. Peritoneal exudate macrophages were stimulated with lipopolysaccharide $(500 \mathrm{ng} / \mathrm{ml})$ and interferon- $\gamma(5 \mathrm{ng} / \mathrm{ml})$ in the presence of various concentrations of physalins B, D, F or G (A), and $2 \mu \mathrm{g} / \mathrm{ml}$ of physalin $\mathrm{B}$ or $1 \mu \mathrm{M}$ of dexamethasone (B). Cell-free supernatants were collected after $24 \mathrm{~h}$ and tested for nitrite production by the Griess assay. Data show the means \pm S.D. of four (A) and five (B) experiments performed. $* P<0.05$ (Newman-Keuls multiple comparison test).
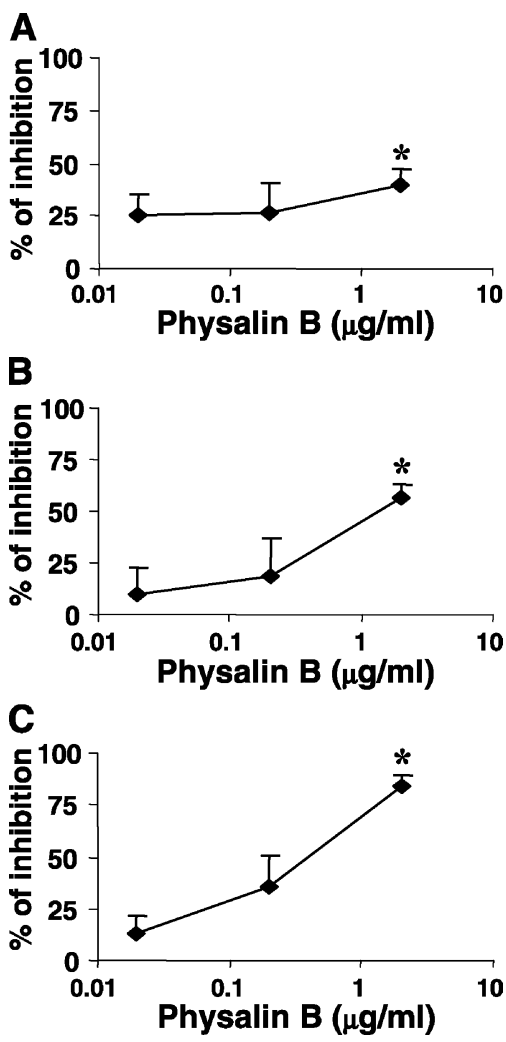

Fig. 2. Modulation of cytokine production by physalin B. Peritoneal exudate macrophages were stimulated in vitro with lipopolysaccharide (500 $\mathrm{ng} / \mathrm{ml}$ ) alone (A and B) or in combination with $5 \mathrm{ng} / \mathrm{ml}$ of interferon- $\gamma(\mathrm{C})$ in the presence of different concentrations of physalin B. Cell-free supernatants were collected after $4 \mathrm{~h}$ (A and B) or $24 \mathrm{~h}(\mathrm{C})$ and tested for production of TNF- $\alpha$ (A), interleukin-6 (B) and interleukin-12 p40 (C) by ELISA. Data represents the means \pm S.D. of three to five experiments. Cytokine levels in lipopolysaccharide control cultures varied from 0.5 to 5 $\mathrm{ng} / \mathrm{ml}$ for TNF- $\alpha, 2$ to $3 \mathrm{ng} / \mathrm{ml}$ for interleukin- 6 and 1 to $6 \mathrm{ng} / \mathrm{ml}$ for interleukin-12. ${ }^{*} P<0.05$ (Newman-Keuls multiple comparison test).

The effects of physalins on NO production by activated macrophages were not due to toxicity, as macrophages cultured in the presence of physalins concentrations below $2.5 \mu \mathrm{g} / \mathrm{ml}$ showed no difference in viability when compared to untreated controls (data not shown).

\subsection{Physalin B modulates cytokine production by activated macrophages}

We then evaluated the effects of physalin B on cytokine production by activated macrophages. Addition of physalin $\mathrm{B}$ to lipopolysaccaride-stimulated peritoneal macrophage cultures induced a decrease of TNF- $\alpha$ and interleukin- 6 production (Fig. 2A and B). Physalin B also caused a dose dependent inhibition in interleukin-12 production stimulated by lipopolysaccaride and interferon- $\gamma$ (Fig. 2C). The inhibition of interleukin-12 production by physalin $\mathrm{B}$ were about $90 \%$ at $2 \mu \mathrm{g} / \mathrm{ml}$, whereas in interleukin- 6 and TNF- $\alpha$ production, the same dose of physalin $\mathrm{B}$ inhibited about $60 \%$ and $30 \%$, respectively (Fig. 2). 


\subsection{Physalins B, F or $G$ protect mice against a lethal lipopolysaccaride challenge}

To investigate the effects of physalins in endotoxic shock, groups of mice were challenged with a lethal dose of lipopolysaccaride and simultaneously treated with doses of 0.5 or $1 \mathrm{mg}$ of physalins B, F or G. All mice in control group showed signs of endotoxemia such as piloerection, shivering and lethargy, and died after 24-36 h. Physalin-treated mice also exhibited endotoxic shock signs, although these were less pronounced than in control mice. More importantly, all mice treated with $1 \mathrm{mg}$ of physalins $\mathrm{B}, \mathrm{F}$ or $\mathrm{G}$ survived the lethal challenge (Fig. 3). At a dose of $0.5 \mathrm{mg} / \mathrm{ml}$, physalins B and $\mathrm{F}$ protected $60 \%$ and $40 \%$ of mice, respectively, whereas treatment with $0.5 \mathrm{mg} / \mathrm{ml}$ of physalin $\mathrm{G}$ had no effect. TNF- $\alpha$ produced by lipopolysaccaride stimulation is a pivotal mediator in various events during endotoxic shock (Remick et al., 1990). As macrophages are a major source of TNF- $\alpha$ and
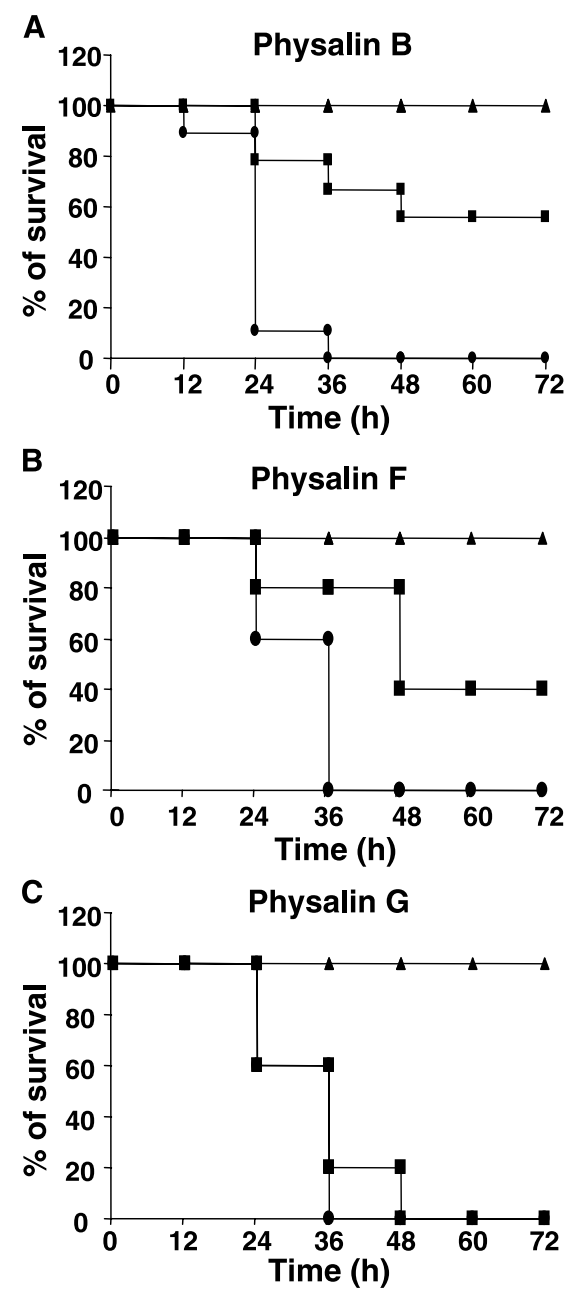

Fig. 3. Treatment of lipopolysaccharide-challenged mice with different physalins. Groups of 10-23 mice were simultaneously injected with $600 \mu \mathrm{g} /$ $\mathrm{ml}$ of lipopolysaccharide (LD 100) and treated with doses of $0.5 \mathrm{mg}$ (squares), $1 \mathrm{mg}$ (triangles) of physalins B, F or G, or saline (circles) intraperitoneally. Lethality was monitored over 4 days.

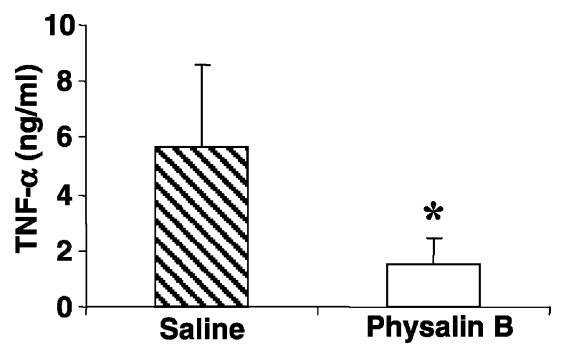

Fig. 4. Reduction of TNF- $\alpha$ production in vivo by physalin B. BALB/c mice were simultaneously injected with $400 \mu \mathrm{g} / \mathrm{ml}$ of lipopolysaccharide and treated with $0.5 \mathrm{mg}$ of physalin B or the same volume of saline. Blood samples from individual mice were collected $90 \mathrm{~min}$ later for TNF- $\alpha$ detection by ELISA. Data represent the means \pm S.D. of five mice per group. $* P<0.05$ (Student's $t$-test).

other proinflammatory cytokines during endotoxic shock, we tested whether physalin B affects lipopolysaccaride-induced TNF- $\alpha$ production in vivo. Treatment of lipopolysaccaridechallenged mice with physalin $B$ caused a reduction in serum TNF- $\alpha$ levels (Fig. 4). Physalin B-treated mice produced three times less TNF- $\alpha$ than control mice $(P<0.02)$.

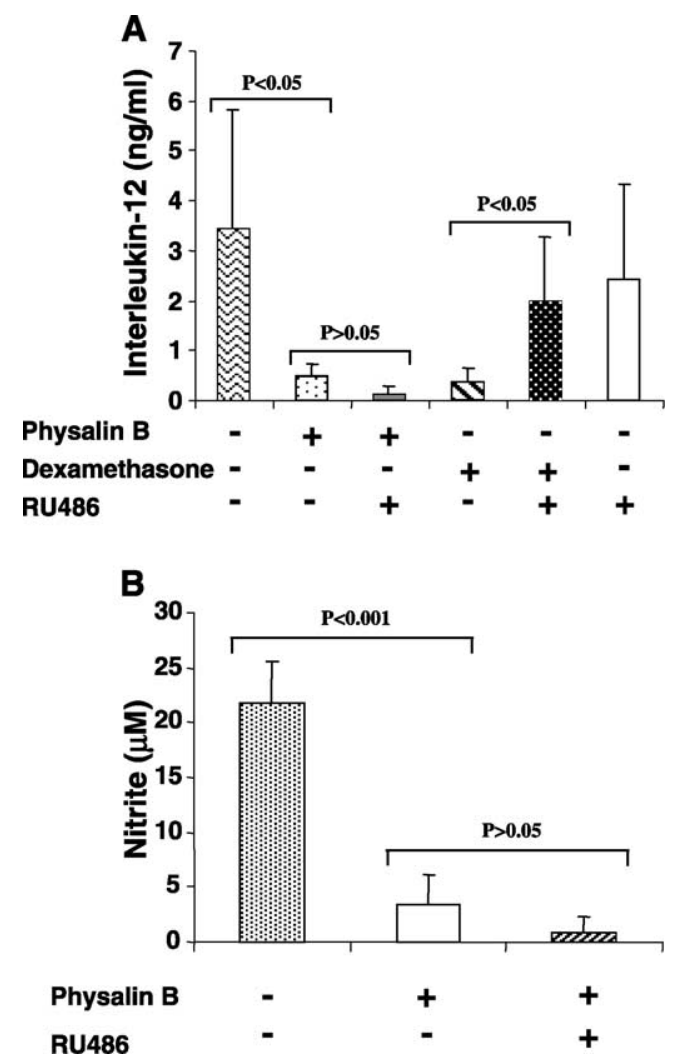

Fig. 5. The glucocorticoid antagonist RU486 does not block the effects of physalin B. Peritoneal exudate macrophages were stimulated with lipopolysaccharide $(500 \mathrm{ng} / \mathrm{ml})$ and interferon- $\gamma(5 \mathrm{ng} / \mathrm{ml})$ and treated with physalin B $(2 \mu \mathrm{g} / \mathrm{ml})$ or dexamethasone $(1 \mu \mathrm{M})$ in the absence or presence of RU486 $(10 \mu \mathrm{M})$. Cell-free supernatants were collected $24 \mathrm{~h}$ later and tested for interleukin-12 p40 (A) or NO (B) production by ELISA or by the Griess assay, respectively. Data represent the means \pm S.D. of four (A) and five (B) experiments. Statistical analyses were carried out using NewmanKeuls multiple comparison test. 
3.4. The glucocorticoid receptor antagonist RU486 does not block the in vitro effects of physalin $B$

Dexamethasone modulates cytokine and NO production, and protects mice against endotoxic shock by interaction with the glucocorticoid receptor, which can be blocked by the receptor antagonist RU486 (Lazar et al., 1992). We tested the ability of RU486 to reverse the action of physalin B in activated macrophage. The addition of RU486 did not block the inhibitory effects of physalin B in interleukin-12 and NO production by stimulated macrophages at of $10 \mu \mathrm{M}$ (Fig. 5) or at concentrations 10- to 100-fold higher (not shown). RU486 also failed to reverse the inhibitory effects of physalins $\mathrm{F}$ and $\mathrm{G}$ in macrophage cultures (data not shown). Addition of RU486 $(10 \mu \mathrm{M})$ to dexamethasone-treated, lipopolysaccaride- and interferon- $\gamma$-stimulated cultures abolished the inhibition of interleukin-12 production (Fig. 5A).

\section{Discussion}

Despite its use in folk medicine, little is known about the pharmacological properties of $P$. angulata and its compounds. In this report, we showed that physalins B, F and $G$ have potent immunosuppressive activities in macrophages and in lipopolysaccaride-induced shock. These seco-steroids may therefore partially account for the antiinflammatory properties of $P$. angulata extracts empirically observed.

Lipopolysaccaride and interferon- $\gamma$ act synergistically in the induction of NO synthesis by macrophages (Lorsbach et al., 1993). Physalins B, F and G showed a potent inhibitory action of NO production by macrophages activated by lipopolysaccaride and interferon- $\gamma$. The inhibition of NO production by the physalins was greater than that of dexamethasone, the gold standard of glucocorticoids. The active physalins reduced by $90-100 \%$ the NO production by macrophages activated with lipopolysaccaride and interferon- $\gamma$, whereas dexamethasone reduced $\mathrm{NO}$ production by $30 \%$. Physalin B also reduced by $100 \%$ the production of NO by peritoneal exudate macrophages with lipopolysaccaride or interferon- $\gamma$ alone (not shown).

TNF- $\alpha$ is a key mediator in septic or endotoxic shock. Administration of TNF- $\alpha$ induces shock, whereas treatment of mice with neutralizing monoclonal antibodies anti-TNF- $\alpha$ prevents the mortality caused by lipopolysaccaride challenge (Kettelhut et al., 1987; Remick et al., 1990). In this work we have showed that physalins inhibit lipopolysaccarideinduced TNF- $\alpha$ production both in vitro and in vivo. However, the protective effect of physalins in endotoxic shock may be due not only to the inhibitory action on TNF- $\alpha$ production, but also to the suppression of other cytokines such as interleukin-6 and interleukin-12, as well as of NO production. Excessive NO production under pathological conditions, such as endotoxemia, can lead to circulatory failure, hypotension, and septic shock (Thiemermann, 1997; Vincent et al., 2000). Moreover, interleukin-12 is a potent inducer of interferon- $\gamma$ (Chan et al., 1991), another cytokine related to lethality in endotoxic shock (Heinzel, 1990). Thus, it is likely that a combination of effects may contribute to protection induced by the physalins in lipopolysaccarideinduced shock.

The effects of physalins on cytokine and NO production were not affected by the presence of the glucocorticoid receptor antagonist RU486. This demonstrates that physalins and dexamethasone suppress macrophage responses through different mechanisms. It was recently demonstrated that RU486 does not block the inhibitory effects of progesterone on NO synthesis by macrophages (Kohmura et al., 2000). The effects of progesterone, but not of dexamethasone, were blocked by another synthetic antagonist, ZK299 [11,-(4dimethyl-aminopropyl)-17-hydroxy-17,-(3-hydroxypropyl)13a-methyl-4,9gonadien-3-one] (Kohmura et al., 2000). As macrophages do not express progesterone receptor mRNA, and binding of progesterone to glucocorticoid receptor has been shown, it is possible that progesterone acts by activation of glucocorticoid receptor through a distinct pathway (Miller et al., 1996). Thus, the active physalins described here may act by the same mechanism used by progesterone. Studies aimed at the investigation of the intracellular mechanisms affected by the physalins are currently being carried out.

Glucocorticoids are among the most widely employed classes of drugs used in a variety of inflammatory and autoimmune diseases. However, the therapeutic use of glucocorticoids is strongly limited by major side effects caused by their wide range of actions, especially during long-term treatment. The search for new natural steroid compounds with similar beneficial activities to the glucocorticoids, but lower deleterious effects, is a promising field of research. This may be achieved by dissociating the transactivation and transrepression intracellular activities of glucocorticoid receptors (Vanden Berghe et al., 1999; Vayssiere et al., 1997). The potential toxicities of physalins remain still to be determined.

\section{Acknowledgements}

This work was supported by grants from (CNPq), Instituto do Milênio do Semi-Árido (IMSEAR-MCT) and FIOCRUZ. The authors wish to thank Dr. Brendan Flannery for careful revision of this manuscript.

\section{References}

Beato, M., Klug, J., 2000. Steroid hormone receptors: an update. Hum. Reprod. Updat. 6, 225-236.

Chan, S.H., Perussia, B., Gupta, J.W., Kobayashi, M., Pospisil, M., Young, H.A., Wolf, S.F., Young, D., Clark, S.C., Trinchieri, G., 1991. Induction of interferon gamma production by natural killer cell stimulatory factor: characterization of the responder cells and synergy with other inducers. J. Exp. Med. 173, 869-879. 
Chiang, H.C., Jaw, S.M., Chen, P.M., 1992a. Inhibitory effects of physalin $\mathrm{B}$ and physalin $\mathrm{F}$ on various human leukemia cells in vitro. Anticancer Res. 12, 155-162.

Chiang, H.C., Jaw, S.M., Chen, C.F., Kan, W.S., 1992b. Antitumor agent, physalin F from Physalis angulata L.. Anticancer Res. 12, 837-843.

Ding, A.H., Nathan, C.F., Stuehr, D.J., 1988. Release of reactive nitrogen intermediates and reactive oxygen intermediates from mouse peritoneal macrophages. Comparison of activating cytokines and evidence for independent production. J. Immunol. 141, 2407-2412.

Duarte, J., Perrière, G., Laudet, V., Robinson-Lechavi, M., 2002. NUREBASE: database of nuclear hormone receptors. Nucleic Acids Res. 30, 364-368.

Heinzel, F.P., 1990. The role of IFN-gamma in the pathology of experimental endotoxemia. J. Immunol. 145, 2920-2924.

Kettelhut, I.C., Fiers, W., Goldberg, A.L., 1987. The toxic effects of tumor necrosis factor in vivo and their prevention by cyclooxygenase inhibitors. Proc. Natl. Acad. Sci. U. S. A. 84, 4273-4277.

Kohmura, Y., Kirikae, T., Kirikae, F., Nakano, M., Sato, I., 2000. Onapristone (ZK299) blocks the suppressive effect of progesterone, but not that dexamethasone, on inducible nitric oxide synthase gene expression and nitric oxide production in murine macrophages. Int. J. Immunopharmacol. 22, 765-774.

Lazar, G. Jr., Lazar, G., Agarwal, M.K., 1992. Modification of septic shock in mice by the antiglucocorticoid RU38486. Circ. Shock 36, $180-184$

Lin, Y.S., Chiang, H.C., Kan, W.S., Hone, E., Shih, S.J., Won, M.H., 1992. Immunomodulatory activity of various fractions derived from Physalis angulata L. extract. Am. J. Chin. Med. 20, 233-243.

Lorsbach, R.B., Murphy, W.J., Lowenstein, C.J., Snyder, S.H., Russell, S.W., 1993. Expression of the nitric oxide synthase gene in mouse macrophages activated for tumor cell killing. Molecular basis for the synergy between interferon-gamma and lipopolysaccharide. J. Biol. Chem. 268, 1908-1913.

Mangelsdorf, D.J., Thummel, C., Beato, M., Herrlich, P., Schutz, G., Umesono, K., Blumberg, B., Kastner, P., Mark, M., Chambon, P., et al., 1995. The nuclear receptor superfamily: the second decade. Cell 83, $835-839$

Matsuura, T., Kawai, M., Nakashima, R., Butsugan, Y., 1970. Structures of physalin A and physalin B, 13,14-Seco-16,24-cyclo-steroids from Physalis alkekengi var. Francheti. J. Chem. Soc. 5, 664-670.

Miller, L., Alley, E.W., Murphy, W.J., Russell, S.W., Hunt, J.S., 1996. Progesterone inhibits inducible nitric oxide synthase gene expression and nitric oxide production in murine macrophages. J. Leukoc. Biol. 59, $442-450$.

Mulchandani, N.B., Iyer, S.S., Badheka, L.P., 1979. Physalin D, a new 1314-Seco-16,24-cyclo steroid from Physalis minima. Planta Med. 37, $268-273$.

Remick, D.G., Strieter, R.M, Eskandari, M.K, Nguyen, D.T., Genord, M.A., Raiford, C.L., Kunkel, S.L., 1990. Role of tumor necrosis factor-alpha in lipopolysaccharide-induced pathologic alterations. Am. J. Pathol. 136, 49-60.

Row, L.R., Sarma, N.S., Reddy, K.S., Matsuura, T., Nakashima, R., 1978. The strutures of physalins $\mathrm{F}$ and $\mathrm{J}$ from Physalis angulata L. and Physalis lancifolia. Phytochemistry 17, 1647-1650.

Row, L.R., Reddy, K.S., Sarma, N.S., Matsuura, T., Nakashima, R., 1980. New physalins from Physalis angulata L. and Physalis lancifolia structures and reactions of physalins D, I, G and K. Phytochemistry 17, $1175-1181$.

Schimmer, B.P., Parker, K.L., 2001. Adrenocorticotropic hormone; adrenocortical steroids and their synthetic analogs; inhibitors of the synthesis and actions of adrenocortical hormones. In: Hardman, J.G., Limbird, L.E., Goodman Gilman, A. (Eds.), The Pharmacological Basis of Therapeutics, 10th ed. McGraw-Hill, New York, pp. 1649-1677.

Thiemermann, C., 1997. Nitric oxide and septic shock. Gen. Pharmacol. 29, $159-166$.

Vanden Berghe, W., Francesconi, E., De Bosscher, K., Resche-Rigon, M., Haegeman, G., 1999. Dissociated glucocorticoids with anti-inflammatory potential reppress interleukin- 6 gene expression by a nuclear factor-kappaB-dependent mechanism. Mol. Pharmacol. 56, 797-806.

Vayssiere, B.M., Dupont, S., Choquart, A., Petit, F., Garcia, T., Marchandeau, C., Gronemeyer, H., Resche-Rigon, M., 1997. Synthetic glucocorticoids that dissociate transactivation and AP-1 transrepression exhibit antiinflammatory activity in vivo. Mol. Endocrinol. 11, $1245-1255$.

Vincent, J.L., Zhang, H., Szabo, C., Preiser, J.C., 2000. Effects of nitric oxide in septic shock. Am. J. Respir. Crit. Care Med. 161, 1781-1785. 